\title{
SPH Simulation on the Coupled Failure of Slope-Building Adjacent to Water Triggered by the Rapid Drawdown of Water Level
}

\author{
Yundong Zhou, ${ }^{1}$ Zhangcheng Qu, ${ }^{2}$ Weijie Zhang ${ }^{(D,}{ }^{1}$ and Zhanbin Wang ${ }^{2}$ \\ ${ }^{1}$ Key Laboratory of Ministry of Education for Geomechanics and Embankment Engineering, Hohai University, Nanjing 210098, China \\ ${ }^{2}$ College of Civil and Transportation Engineering, Hohai University, Nanjing 210098, China
}

Correspondence should be addressed to Weijie Zhang; zhangwj2016@hhu.edu.cn

Received 10 January 2019; Revised 20 March 2019; Accepted 23 April 2019; Published 8 May 2019

Academic Editor: Elisa Francomano

Copyright (c) 2019 Yundong Zhou et al. This is an open access article distributed under the Creative Commons Attribution License, which permits unrestricted use, distribution, and reproduction in any medium, provided the original work is properly cited.

With the development of economy, more and more buildings are constructed on both sides of rivers. The rapid drawdown of water level may induce the change of groundwater seepage in the river bank, thus affecting the stability of buildings on the bank. In this study, the right bank of Qinhuai river with its ancillary building from the Dinghuai Gate to the Qingliang Gate in Nanjing City is analyzed to reveal the failure mechanism and coupled failure mode of slope and building adjacent to water. The soil-water coupled SPH program considering the interaction between soil and structure has been proposed. Then this model is used to study the evolutionary deformation mechanism of slope and building under the rapid drawdown of water level. The results indicate that the potential slip surface of slope and the asymmetrical distribution of plastic zone in the foundation of building become more obvious under the rapid drawdown of water level. Besides, the differential settlement of building induced by the rapid drawdown causes the building tilt. When the sliding surface of the slope passes the building, the differential settlement will become larger. This study is conducive to reveal the coupled failure mechanism of slope and building and also to provide scientific basis for the prevention of such disasters.

\section{Introduction}

Rapid drawdown of the water level refers to the situation that the river level drops rapidly outside the slope where a building is located [1]. Under this circumstance, water inside the slope cannot drain away immediately and the seepage line in the slope basically remains unchanged. By contrast, the boundary conditions of the seepage would be changed, resulting in deterioration of slope stability. Lots of landslides have occurred under the rapid drawdown of water level. In the United States, about 30\% of landslides occurred near the Roosevelt lake, when the water level dropped by $10 \sim 20$ meters from 1941 to 1953 [2]. In Spain, a large landslide about $40 \times 10^{6} \mathrm{~m}^{3}$ was reactivated on the left bank of Canelles Reservoir due to drawdown in the summer of 2006 after keeping the high water level for 10 years [3]. In China, the Qianjiangping landslide occurred due to the water level variation of the Three Gorges reservoir on July
14, 2003, which destroyed 4 factories and 129 houses with 24 casualties and 1,200 homeless people [4]. According to the field investigation, the water level of rivers, reservoirs, and canals would drop rapidly after the flood, which would lead the bank slope to landslide, which is adjacent to the water [5]. Therefore, it is urgent to study the failure mechanism of slope under the rapid drawdown of water level.

A large number of methods, including theoretical analyses, model experiments, and numerical simulations, have been introduced to investigate the slope stability under the drawdown of water level from the perspective of pore water pressure inside the water-facing slope and water pressure on the slope caused by the water level of river. Viratjandr [6] used the kinematic limit analysis approach to examine the stability of slope subjected to a rapid or slow drawdown. Based on the theory of limit analysis, Gao [7] discussed the three-dimensional effect of slope under the condition of water level plummeting and found that the plane strain 


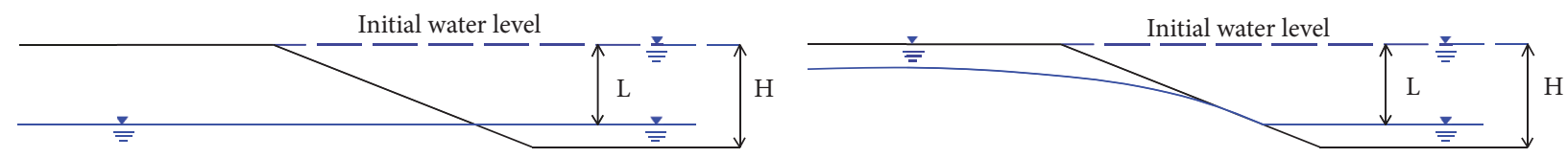

(a)

(b)

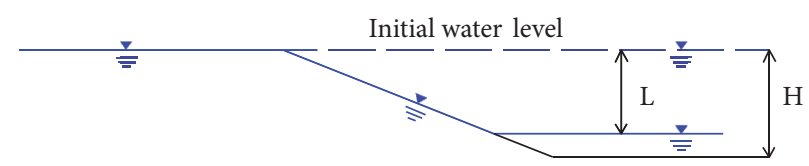

(c)

Figure 1: Phreatic level after drawdown: (a) slow drawdown, (b) transient drawdown, and (c) rapid drawdown (based on Berilgen [13]).

analysis was suitable to evaluate the stability of the waterfacing slope when the aspect ratio was greater than 10 . Meanwhile, some researchers studied the failure mechanism, the failure mode, and the deformation mechanism of waterfacing slope by large-scale model tests and centrifuge tests [8-12]. Berilgen [13] classified the drawdown of water level as three cases shown in Figure 1. For the first case, illustrated in Figure 1(a), the soil was totally drained during the process of drawdown, which was called "slow drawdown." For the generally transient drawdown case shown in Figure 1(b), coupled seepage and consolidation analyses could be carried out concurrently in the stability analysis. For the third case, plotted in Figure 1(c), the soil was considered to be undrained and it was called "rapid drawdown." "Slow drawdown" and "rapid drawdown" represented the extreme situations in which seepage and consolidation analyses were not done prior to the stability analysis. Berilgen obtained a conclusion similar to the study of Viratjandr [6] with the finite element analysis. The rapid drawdown with the minimum safety coefficient and slow drawdown with the maximum safety coefficient were two extreme situations that affect the slope stability. As the "rapid drawdown" was the most dangerous among three cases, many researchers studied the stability of the slope adjacent to water under rapid drawdown through the simplified model of Figure 1(c) [1, 3, 13-15]. Besides, considering the different infiltration rates, Desai [16] used a numerical approach to locate the internal infiltration line and estimated the global factor of safety with the limit analysis. Desai's analysis could be considered as a representative of semirapid drawdown and the results showed that the FOS was $40 \%$ higher than that of rapid drawdown in some cases. Griffiths et al. [14, 15, 17] analyzed the adverse effects of various factors on the slope including the decreasing amount and speed of water level and the soil permeability coefficient.

As a conclusion, theoretical methods based on the rigid limit equilibrium equation can be used to study the change of slope safety coefficient when the water level drops rapidly, while it cannot take the deformation of the slope into account. Besides, experimental methods can reproduce the instability process of water-facing slope under the sudden drawdown of water level, but the cost is too high and it is inconvenient to perform parameter analysis based on experimental methods. Numerical analyses can take into account the influence of various factors on the stability of water-facing slope, but there was a large deformation after the slope failure according to the experimental phenomenon. Traditional numerical methods, for instance, FEM and FDM, cannot deal with the large deformation due to the constraints of grids. There is no grids constraint for the method of smoothed particle hydrodynamics (SPH), which can simulate the large deformation and failure process of slopes [18-20]. However, the coupled failure process of slope and building under the action of water level drawdown is rarely studied. In addition, the stability of building on the top of slope is more important than the stability of the slope itself, so it is significant to study the coupled failure process of slope and building.

Therefore, the soil-water coupling and the soil-structure interaction have been introduced into the SPH method in this study. For the soil-water coupling, the fluid phase (pore water) and the solid phase (soil or structure) are simulated on different layers which have the interaction force. With regard to the soil-structure interaction, the coupling force between soil and structure is realized by the reaction force that is the same in size and opposite in direction. Then, the cases of a large-scale model test and a retaining wall are adopted to validate the interaction algorithms. Finally, the right bank of Qinhuai river and its ancillary building from the Dinghuai Gate to the Qingliang Gate in Nanjing City are analyzed to reveal the coupled failure mechanism and failure mode of slope and building adjacent to the river.

\section{Water-Soil Coupled SPH Numerical Framework}

2.1. Basic Concepts. The basic idea of SPH is to discretize the spatially continuous entity into series of particles that can carry mass, speed, stress, and deformation information. There is no link between these particles. By providing an accurate numerical solution for hydrodynamic equations and tracking the movement of each particle, this method can describe the mechanical behavior of an entire system [2125]. The meshless characteristics of SPH make it easier to deal with the large deformation problem, sequentially eliminating the mesh distortion problems compared with the traditional Lagrange method [26-30].

The cores of this method are the field function approximation and the particle approximation, respectively [31]. The field function approximation refers to the integral expression 


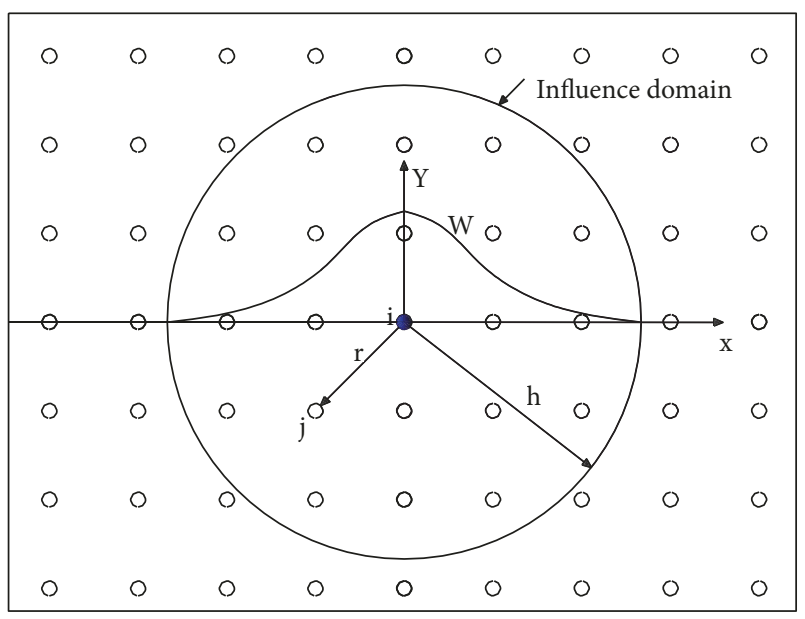

FIgURE 2: Particle approximation in the SPH method.

of the macroscopic variables (such as density, pressure, and acceleration) and the particle approximate means that the weighted summation of motion information is calculated from particles within the influence radius (Figure 2).

The particle approximate function and its derivative can be expressed as follows:

$$
\begin{gathered}
\langle f(x)\rangle=\sum_{j=1}^{N} m_{j} \frac{f_{j}\left(x^{\prime}\right)}{\rho_{j}} W\left(x-x^{\prime}, h\right) \\
\frac{\partial\langle f(x)\rangle}{\partial x_{i}}=\sum_{j=1}^{N} \frac{m_{j}}{\rho_{j}} f_{j}\left(x^{\prime}\right) \frac{\partial W\left(x-x^{\prime}, h\right)}{\partial x_{i}}
\end{gathered}
$$

where $f(x)$ is the field function; $\boldsymbol{x}$ is the position vector of a computing particle; $\boldsymbol{x}^{\prime}$ is the position vector of a supporting particle; $h$ is the smoothing length; $N$ is the number of supporting particles inside the influence domain; $m$ is the mass; $\rho$ is the density; and $W$ is the smooth kernel function.

2.2. Mixture Theory for the Two-Phase Coupled Soil. For the complex pore geomaterial, the pore water pressure generated by the flow of pore water has a great influence on the physical and mechanical properties of soil skeleton. The Biot consolidation theory is introduced into the SPH numerical framework due to its wide application. In the proposed SPH method, the fluid phase (pore water) and the solid phase (soil and structure) are simulated on different layers (Figure 3 ). Accordingly, physical quantities can be distributed according to the following formulas:

$$
\begin{aligned}
\bar{\rho}^{w} & =n \rho^{w} \\
\sigma_{m n}^{w} & =n p^{w} \delta_{m n}
\end{aligned}
$$

(pore water)

$$
\begin{aligned}
\bar{\rho}^{s} & =(1-n) \rho^{s} \\
\sigma_{m n}^{s} & =(1-n) p^{w} \delta_{m n}+\sigma_{m n}^{\prime} \quad \text { (soil or structure) } \\
\rho & =(1-n) \rho^{s}+n \rho^{w} \\
\sigma & =p^{w} \delta_{m n}+\sigma_{m n}^{\prime}
\end{aligned}
$$

(total)

where $\rho^{\mathrm{w}}$ is the density of water; $\rho^{\mathrm{s}}$ the density of soil or structure; $p^{\mathrm{w}}$ is the pore water pressure; $n$ is the porosity ( $n$ $=0$, when solid particles are structural particles); $\sigma^{\prime}$ is the effective stress; and $\delta_{i j}$ is the Kronecker function.

The controlling equations of SPH are the continuity equation, the momentum equation, and the energy equation, respectively. This study assumes that the temperature of liquid phase in the geomaterial remains constant, so the energy equation is not considered. The controlling equations of SPH can be obtained by using (1) and (2) for the liquid phase and the solid phase.

The equation of continuity is

$$
\frac{d \bar{\rho}_{i}}{d t}=\sum_{j=1}^{N} m_{j}\left(v_{i m}-v_{j m}\right) \frac{\partial W_{i j}}{\partial x_{i m}}
$$

The momentum equation of pore water is

$$
\begin{aligned}
\frac{d v_{i m}^{w}}{d t}= & \sum_{j=1,}^{N} m_{j \in w a t e r}\left(\frac{\sigma_{i m n}^{w}}{\left(\bar{\rho}_{i}^{w}\right)^{2}}+\frac{\sigma_{j m n}^{w}}{\left(\bar{\rho}_{j}^{w}\right)^{2}}\right) \frac{\partial W_{i j}}{\partial x_{i n}}+F_{i} \\
& +\frac{R_{i m}^{s w}}{\bar{\rho}_{i}^{w}}
\end{aligned}
$$

The momentum equation of soil or structure is

$$
\begin{aligned}
& \frac{d v_{i m}^{s}}{d t}=\sum_{j=1, j \in s o i l}^{N} m_{j}\left(\frac{\sigma_{i m n}^{s}}{\bar{\rho}_{i}^{s 2}}+\frac{\sigma_{j m n}^{s}}{\bar{\rho}_{j}^{s 2}}-\delta_{m n} \Pi_{i j}\right. \\
& \left.\quad+f r_{i j m n}\right) \frac{\partial W_{i j}}{\partial x_{i n}}+F_{i}+\frac{R_{i m}^{w s}}{\bar{\rho}_{i}^{s}}
\end{aligned}
$$

where $v$ is the velocity vector; $m$ and $n$ indicate the directions of coordination; $i$ indicates the computing particle; $j$ indicates the supporting particle; $\boldsymbol{\sigma}^{\mathbf{w}}$ is the pore water stress vector; $\boldsymbol{\sigma}^{\boldsymbol{s}}$ is the soil or structure stress vector; $F_{i}$ is the external force. $R^{\mathrm{sw}}$ and $R^{\mathrm{ws}}$ are the interaction force between the pore water and the soil or the structure. $\Pi_{i j}$ is the artificial viscosity that can correct numerical oscillation during the calculation [32].

Water is an incompressible fluid that is difficult to model. Therefore, artificial compressibility is introduced and the pore water is assumed as a kind of compressible fluid that can obtain large pressure changes through small density changes. In addition, the coefficient of viscosity is also considered to acquire the revised formula of pore water pressure (details in [31]). 


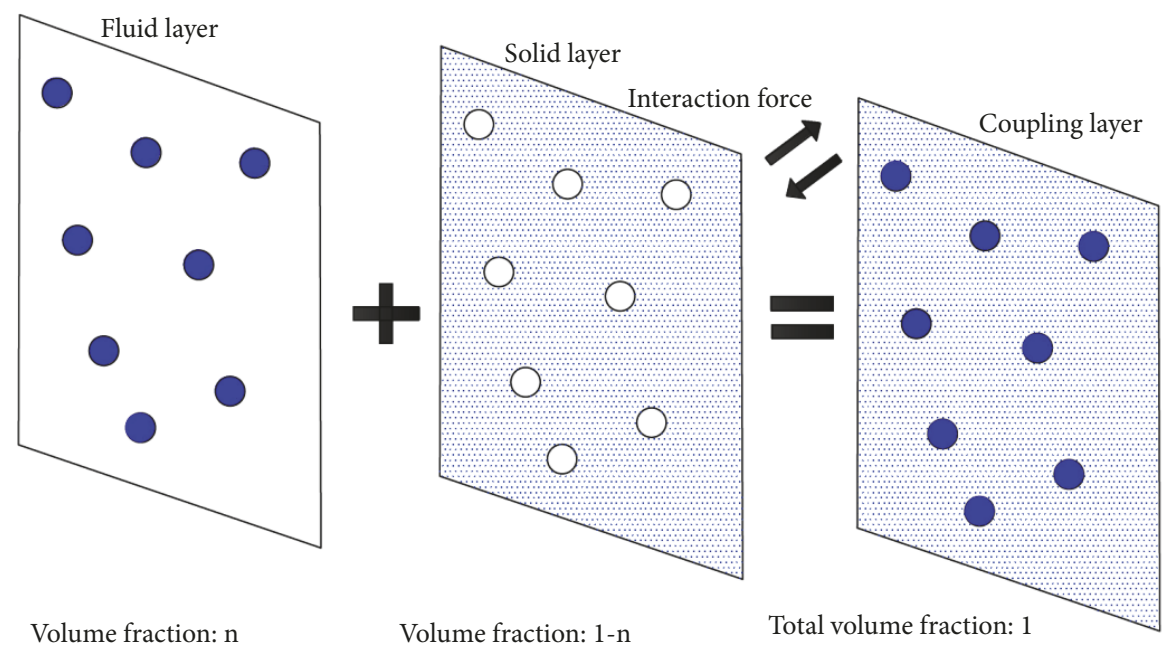

FIGURE 3: Soil-water coupling in the SPH method.

The interaction force between pore water and soil or structure is calculated as [33]

$$
\begin{aligned}
R_{i m}^{s w} & =\sum_{j=1 \in \text { soil }}^{N} m_{j} \frac{R_{i j m}}{\rho_{j}} W_{i j}, \\
R_{i j m} & =n^{2} \frac{\rho^{w} g}{k_{j}}\left(v_{j m}^{s}-v_{i m}^{w}\right) \\
R_{i m}^{w s} & =\sum_{j=1 \in w a t e r}^{N} m_{j} \frac{R_{i j m}}{\rho_{j}} W_{i j}, \\
R_{i j m} & =n^{2} \frac{\rho^{w} g}{k_{i}}\left(v_{j m}^{w}-v_{i m}^{s}\right)
\end{aligned}
$$

where $k$ is the permeability coefficient and $g$ is the gravitational acceleration.

\subsection{Constitutive Model and Interaction of Soil and Structure}

2.3.1. Soil Constitutive Modeling. In this paper, the elastoplastic constitutive model is used to describe the stressstrain relationship of soil. In the framework of plasticity deformation theory, the total strain tensor of an elastoplastic material $\dot{\varepsilon}$ is decomposed into two parts: an elastic strain rate tensor $\dot{\varepsilon}_{e}^{\alpha \beta}$ and plastic strain rate tensor $\dot{\varepsilon}_{p}^{\alpha \beta}$.

$$
\dot{\varepsilon}=\dot{\varepsilon}_{e}^{\alpha \beta}+\dot{\varepsilon}_{p}^{\alpha \beta}
$$

The elastic strain rate tensor $\dot{\varepsilon}_{e}^{\alpha \beta}$ is given by a generalized Hooke law and the plastic strain rate tensor is calculated by plastic flow rule.

$$
\begin{aligned}
& \dot{\varepsilon}_{e}^{\alpha \beta}=\frac{\dot{s}^{\alpha \beta}}{2 G}+\frac{1-2 v}{E} \dot{\sigma}^{m} \delta^{\alpha \beta} \\
& \dot{\varepsilon}_{p}^{\alpha \beta}=\dot{\lambda} \frac{\partial g}{\partial \sigma^{\alpha \beta}}
\end{aligned}
$$

where $\dot{s}^{\alpha \beta}$ is the deviatoric shear stress tensor; $G$ is the shear modulus; $E$ is the elastic Young's modulus; $v$ is Poisson's ratio; $\dot{\sigma}^{m}$ is the mean stress; and $\dot{\lambda}$ is the rate form of plastic multiplier (when the model is in an elastic state, $\dot{\lambda}=0$; when the model produces plastic deformation, $\dot{\lambda}>0$ ). In this study, the Drucker-Prager model (the DP model for short) with associated flow rule is applied to model the mechanical behavior of soil, which is that the plastic potential function $g$ agrees with the yield function $f$ :

$$
g=f\left(I_{1}, J_{2}\right)=\sqrt{J_{2}}+\alpha_{\phi} I_{1}-k_{c}
$$

where $I_{1}$ and $J_{2}$ are, respectively, the first and second invariants of stress tensors:

$$
\begin{aligned}
& I_{1}=\frac{\sigma^{x x}+\sigma^{y y}+\sigma^{z z}}{3} \\
& J_{2}=\frac{1}{2} s^{\alpha \beta} s^{\alpha \beta}
\end{aligned}
$$

where $\alpha_{\phi}$ and $k_{c}$ are Drucker-Prager constants, which are calculated from the Coulomb material constants $c$ (cohesion) and $\phi$ (internal friction). For the plane-strain problem, the Drucker-Prager's constants are computed by

$$
\begin{aligned}
& \alpha_{\phi}=\frac{\tan \phi}{\sqrt{9+12 \tan ^{2} \phi}} \\
& k_{c}=\frac{3 c}{\sqrt{9+12 \tan ^{2} \phi}}
\end{aligned}
$$

Substituting (12) and (13) into (11) and adopting the Jaumann stress rate for large deformation treatment, the 


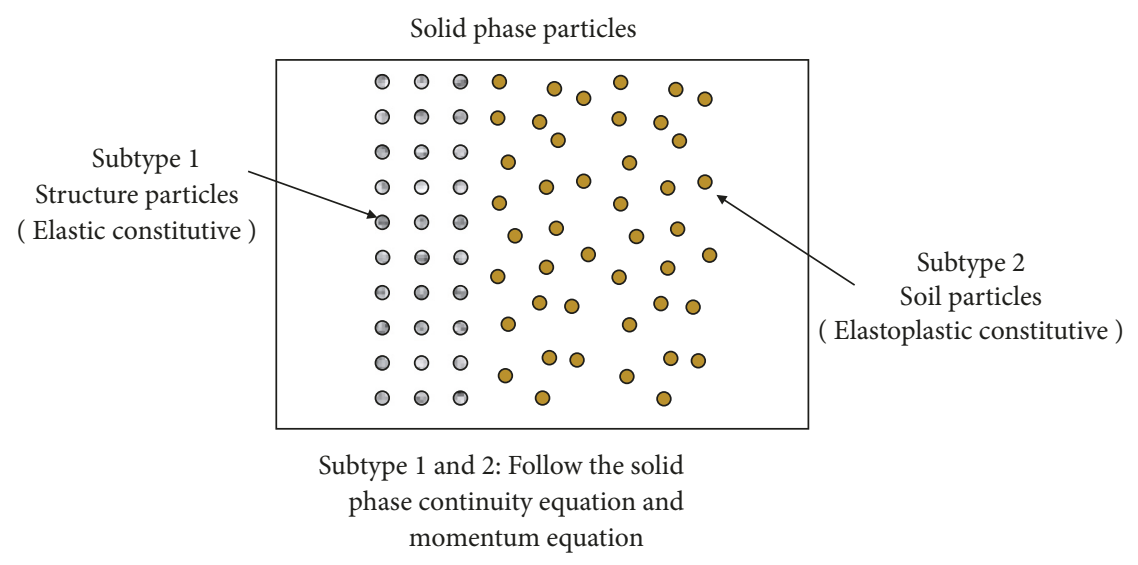

FIGURE 4: Sketch map of soil and structure interaction.

stress-strain relationship for the current soil model at particle $i$ can be derived to be

$$
\begin{aligned}
\frac{d \sigma_{i}^{\alpha \beta}}{d t}= & \sigma_{i}^{\alpha \gamma} \dot{\omega}_{i}^{\beta \gamma}+\sigma_{i}^{\gamma \beta} \dot{\omega}_{i}^{\alpha \gamma}+2 G_{i} \dot{e}_{i}^{\alpha \beta}+K_{i} \dot{\varepsilon}_{i}^{\gamma \gamma} \delta_{i}^{\alpha \beta} \\
& -\dot{\lambda}_{i}\left[3 \alpha_{\phi} K_{i} \delta_{i}^{\alpha \beta}+\left(\frac{G}{\sqrt{J_{2}}}\right)_{i} s_{i}^{\alpha \beta}\right] \\
\dot{\lambda}_{i}= & \frac{3 \alpha_{\phi} K \dot{\varepsilon}_{i}^{\gamma \gamma}+\left(G / \sqrt{J_{2}}\right)_{i} s_{i}^{\alpha \beta} \dot{\varepsilon}_{i}^{\alpha \beta}}{9 \alpha_{\phi}{ }^{2} K_{i}+G_{i}}
\end{aligned}
$$

where $K$ is elastic bulk modulus; $\dot{\varepsilon}^{\alpha \beta}$ and $\dot{\omega}^{\alpha \beta}$ are the strain rate and spin rate tensors defined by

$$
\begin{aligned}
\dot{\varepsilon}_{i}^{\alpha \beta} & =\frac{1}{2}\left(\frac{\partial v^{\alpha}}{\partial x^{\beta}}+\frac{\partial v^{\beta}}{\partial v^{\alpha}}\right)_{i}=\frac{1}{2}\left[\sum_{j=1}^{N} \frac{m_{j}}{\rho_{j}}\left(v_{j}^{\alpha}-v_{i}^{\alpha}\right) \frac{\partial W_{i j}}{\partial x_{i}^{\beta}}\right. \\
& \left.+\sum_{j=1}^{N} \frac{m_{j}}{\rho_{j}}\left(v_{j}^{\beta}-v_{i}^{\beta}\right) \frac{\partial W_{i j}}{\partial x_{i}^{\alpha}}\right] \\
\dot{\omega}_{i}^{\alpha \beta} & =\frac{1}{2}\left(\frac{\partial v^{\alpha}}{\partial x^{\beta}}-\frac{\partial v^{\beta}}{\partial v^{\alpha}}\right)_{i}=\frac{1}{2}\left[\sum_{j=1}^{N} \frac{m_{j}}{\rho_{j}}\left(v_{j}^{\alpha}-v_{i}^{\alpha}\right) \frac{\partial W_{i j}}{\partial x_{i}^{\beta}}\right. \\
& \left.-\sum_{j=1}^{N} \frac{m_{j}}{\rho_{j}}\left(v_{j}^{\beta}-v_{i}^{\beta}\right) \frac{\partial W_{i j}}{\partial x_{i}^{\alpha}}\right]
\end{aligned}
$$

The above soil constitutive model requires five soil parameters: cohesion $(c)$, friction angle $(\phi)$, elastic Young's modulus $(E)$, Poisson's ratio $(v)$, and soil density $(\rho)$. The detailed information can be found in literature [31].

2.3.2. Constitutive Model for Structure. The mechanical behavior of the structure is described by an elastic model, where the stress-strain relationship can be represented as

$$
\dot{\sigma}_{m n}^{e}=D_{m n k l}^{e} \dot{\varepsilon}_{k l}^{e}
$$

where $\dot{\sigma}_{m n}^{e}$ is elastic stress tensor, $D_{m n k l}^{e}$ is a fourth-order elastic coefficient tensor, and $\dot{\varepsilon}_{k l}^{e}$ is the elastic strain tensor.

Given Young's modulus $E$ and Poisson's ratio $v$, the elastic coefficient matrix is

$$
[E]=\left[\begin{array}{cccccc}
\lambda+2 v & \lambda & \lambda & 0 & 0 & 0 \\
\lambda & \lambda+2 v & \lambda & 0 & 0 & 0 \\
\lambda & \lambda & \lambda+2 v & 0 & 0 & 0 \\
0 & 0 & 0 & v & 0 & 0 \\
0 & 0 & 0 & 0 & v & 0 \\
0 & 0 & 0 & 0 & 0 & v
\end{array}\right]
$$

2.3.3. Interaction between Soil and Structure. In the proposed SPH model, soil particles and structural particles are both solid particles and their controlling equations are the continuity equation and momentum equation for the solid phase. To distinguish soil and structure and to simulate the interaction between them, different subtypes are set in the solid phase to represent the soil particles and the structural particles, respectively, as shown in Figure 4.

To facilitate the analysis, it can be assumed that the interaction between soil and structure passes through the reaction force that is the same in size and opposite in direction. In the proposed SPH model, the contact stress between soil and structure has an impact on each other's acceleration. Thus, under the soil-structure interaction, the momentum equation of a structure particle can be expressed as

$$
\begin{aligned}
\frac{d v_{i}^{\alpha}}{d t}= & \sum_{\substack{j=1, j \in \text { soil } \\
i \in \text { structure }}}^{N} m_{j}\left(\frac{\sigma_{i}^{\alpha \beta}}{\bar{\rho}_{i}^{2}}+\frac{\sigma_{j}^{\alpha \beta}}{\bar{\rho}_{j}^{2}}-\delta^{\alpha \beta} \Pi_{i j}\right) \frac{\partial W_{i j}}{\partial x_{i}^{\beta}} \\
& +\frac{F_{i}}{\rho_{i}}
\end{aligned}
$$


Similarly, the momentum equation of a soil particle can be expressed as

$$
\begin{aligned}
\frac{d v_{i}^{\alpha}}{d t}= & \sum_{\substack{j=1, i \in \text { soil } \\
j \in \text { structure }}}^{N} m_{j}\left(\frac{\sigma_{i}^{\alpha \beta}}{\bar{\rho}_{i}^{2}}+\frac{\sigma_{j}^{\alpha \beta}}{\bar{\rho}_{j}^{2}}-\delta^{\alpha \beta} \Pi_{i j}\right) \frac{\partial W_{i j}}{\partial x_{i}^{\beta}} \\
& +\frac{F_{i}}{\rho_{i}}
\end{aligned}
$$

where $\alpha$ and $\beta$ indicate the direction of coordination.

It can be observed that the accelerations of soil and structure have same magnitude and opposite direction under the reaction force. To some extent, the condition of soilstructure deformation coordination is satisfied. Therefore, in theory, the soil-structure interaction treatment method proposed in the present study can be employed to solve the problem of soil-structure interaction in the practical engineering.

In present paper, the linked-list searching method is adopted as the particle searching method. The time integration uses the second-order Runge-Kutta integral method. Besides, the boundary treatment method of Takeda [34] and Morris [35] is adopted to calculate the resisting effect of boundary particles on free particles. This method assumes that the influence of boundary particles on the velocity of free particles is related to the velocity difference and relative distance between them. More details can be found in literature of Zhang [33].

\section{Model Validation}

3.1. Validation of the Soil-Water Coupling Algorithm. In order to validate the feasibility of the proposed SPH model on the calculation of slope failure process caused by rapid drawdown of water level, the same SPH model as the test in Jia [8] is established, and the simulated results are compared with the test results. According to the experiment, the cohesion of silt is $1 \mathrm{kPa}$, the internal friction angle is $30^{\circ}$, and the permeability coefficient is $5.3 \times 10^{-6} \mathrm{~m} / \mathrm{s}$. A total of 13,023 particles are used in this simulating case, consisting of 936 boundary particles, 5,911 soil particles, and 6,176 water particles. The soil constitutive model adopts the DP model and the incremental time step is $5.0 \times 10^{-5} \mathrm{~s}$.

Figure 5 is the comparison of displacement magnitude between experiment and simulation at different states. As shown in Figure 5(b), the water level decreases from 5.6 $\mathrm{m}$ to $3 \mathrm{~m}$. Blocks 1,2 , and 3 are sliders that are observed from the model test, and the frame line presents the side slope shape before collapse. Besides, the color chart of total displacement obtained by SPH simulation after sliding shows that the sliding body (red area) is similar to the sum of sliding blocks 1, 2, and 3 (as shown in Figure 5(b)). Meanwhile, the total displacement of slope crest is $0.48 \mathrm{~m}$, which is close to $0.5 \mathrm{~m}$ measured by the test. This method only considers the situation of sudden drop of water level, assuming that there is no significant drainage outward from the slope, and does not consider the long-term change of seepage field with time. The morphology and displacement of the slope after sliding are
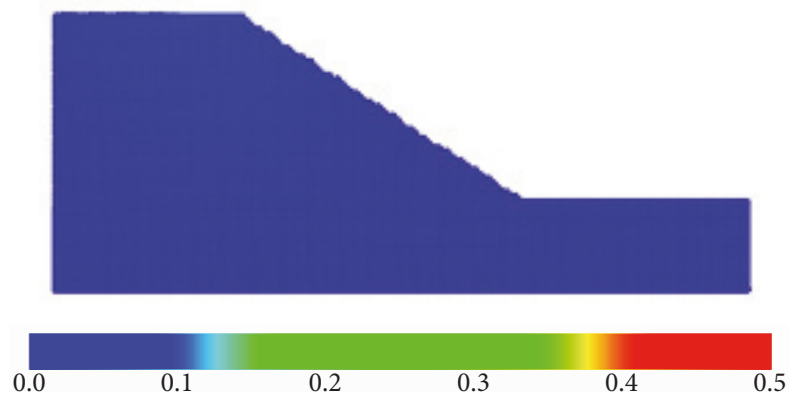

(a) Initial state

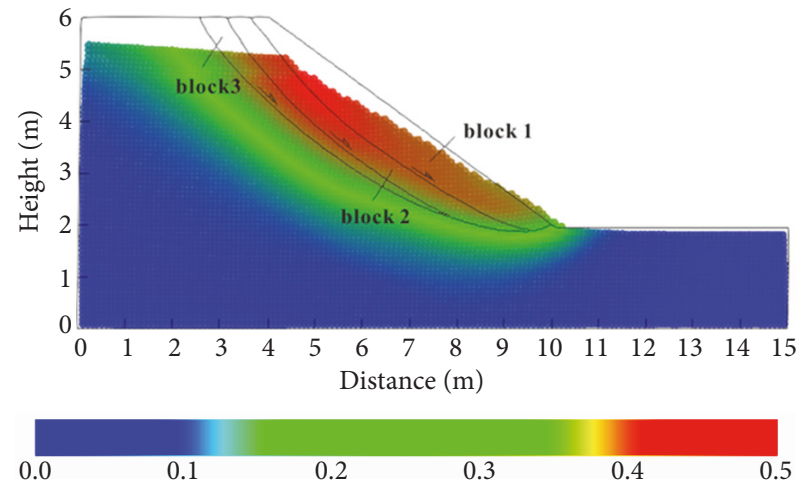

(b) Collapse state

FIgURE 5: Displacement magnitude of the experiment and the simulation (unit: $\mathrm{m}$ ).

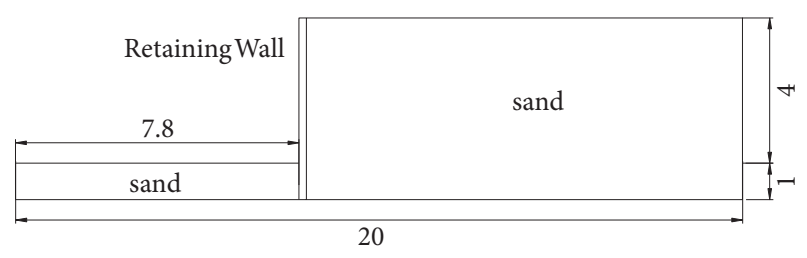

FIGURE 6: Model of retaining wall (unit: $\mathrm{m}$ ).

similar to those obtained from the model test, so it proves that the proposed SPH model can be used to simulate the failure process of soil slope under the rapid drawdown of water level.

3.2. Validation of the Soil-Structure Interaction Algorithm. The retaining wall is a classical problem for the soil-structure interaction in soil mechanics, so it can verify the rationality of soil-structure interaction proposed in the present paper. As shown in Figure 6, the total length of the plate pile in the calculation example is $5 \mathrm{~m}$ and the plate pile is embedded in the soil for $1 \mathrm{~m}$. In this model, sand is adopted as the backfill. Its density and internal friction angle are considered to be $1460 \mathrm{~kg} / \mathrm{m}^{3}$ and $17^{\circ}$, respectively. In the SPH simulation, the stress-strain relationship of soil is expressed by the DP model, while the pipe (structure) is treated as an elastic solid material.

According to the Rankine earth pressure theory, when the soil is in the limit failure state of active earth pressure, the horizontal direction will be the maximal principal stress 
TABLE 1: Parameter of soil and structure.

\begin{tabular}{lccccccc}
\hline Type & $\begin{array}{c}\text { Density } \\
\left(\mathrm{kg} / \mathrm{m}^{3}\right)\end{array}$ & Porosity & $\begin{array}{c}\text { Elasticity } \\
\text { modulus (MPa) }\end{array}$ & Poisson ratio & $\begin{array}{c}\text { Permeability } \\
(\mathrm{m} / \mathrm{s})\end{array}$ & $\begin{array}{c}\text { Particle } \\
\text { spacing } \\
(\mathrm{m})\end{array}$ & $\begin{array}{c}\mathrm{c} \\
(\mathrm{kPa})\end{array}$ \\
\hline Soil (silt) & 1850 & 0.885 & 5 & 0.3 & $7.68 \times 10^{-6}$ & 0.2 & 25 \\
\hline Structure & 1000 & 1 & 1000 & 0.2 & $1 \times 10^{-10}$ & 0.2 & - \\
\hline
\end{tabular}

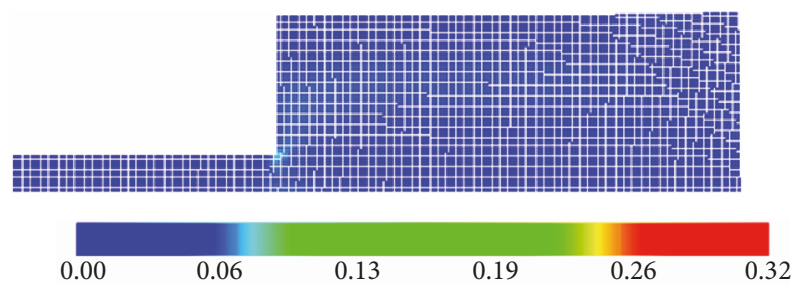

(a) Initial state

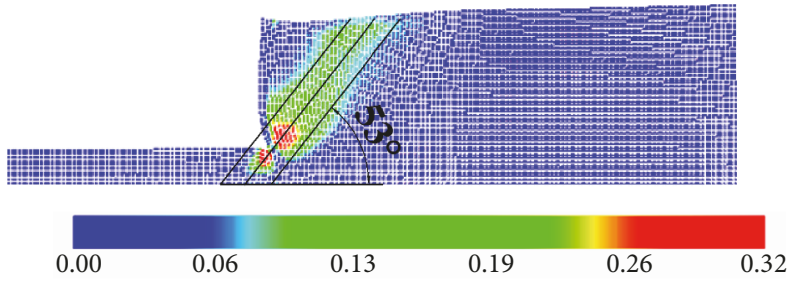

(b) Collapse state

Figure 7: Plastic zone of soil.

plane, and the failure surface angle is $\theta_{f}=45^{\circ}+\varphi / 2=53.5^{\circ}$. A plastic zone of failure state can be observed from Figure 7(b). It can be seen that the angle between the plastic zone and horizontal line is $53^{\circ}$ which is almost the same as the Rankine earth pressure theory.

Curves of horizontal earth pressure with depth are shown in Figure 8(a). The red curve is simulated by $\mathrm{SPH}$ and the black line is calculated by Rankine earth pressure theory. The plate pile wall has both rotary and translational movements, resulting in the nonlinear distribution of earth pressure along the depth. When the soil behind the wall (less than $4.2 \mathrm{~m}$ ) has large deformation due to the excessive active earth pressure, the earth pressure obtained by SPH simulation is less than that of Rankine active earth pressure, which is because the $\mathrm{SPH}$ algorithm takes into account the friction between the wall and soil. As shown in Figure 8(b), the variation of horizontal earth pressure with depth simulated by SPH is similar to the result of the other research [36]. At the same time, the distribution rule of upper earth pressure (less than $1 \mathrm{~m}$ ) along the depth simulated by SPH is more accurate than the FEM result [36].

Above all, the angle between the failure surface and horizontal plane simulated by SPH is almost the same as the Rankine active earth pressure theory. The variation of horizontal earth pressure with depth simulated by SPH is also similar to the result of the other methods [36]. So it has been proven that SPH can simulate the interaction force between soil and structure.

\section{Simulation of Slope-Building-Coupled Failure under the Rapid Drawdown of Water Level}

4.1. Simulating Cases. According to the field investigation, the cross-section diagram of a building on the right bank of Qinhuai river from the Dinghuai Gate to the Qingliang Gate in Nanjing city is selected and discretized into a particle model as shown in Figure 9. The distance $(d)$ between the building and the slope crest is $8 \mathrm{~m}$ under practical conditions, and the dashed blue line refers to the groundwater level. According to the geological report, the soil parameters of this slope are shown in Table 1, where the density of structure particles is equal to the mass of the whole building divided by the total volume. In order to simulate the large deformation of soil, the constitutive behavior of soil is described by the DP model, while the structure is described by the elastic model. In the calculation, there are 27,358 particles, consisting of 1,476 boundary particles, 11,859 water particles, 10,643 soil particles, and 3,380 structure particles. Besides, the incremental time step is $1.2 \times 10^{-4} \mathrm{~s}$ and total steps are $8 \times 10^{4}$.

Based on previous simplified model for rapid drawdown, this paper analyzes the coupled failure of slope and building adjacent to river triggered by the rapid drawdown. The model of the water-soil coupling problem is shown in Figure 9 and the rapid drawdown problems are evaluated as the following three cases: (i) the water level is $11.6 \mathrm{~m}$, (ii) the water level is $8.3 \mathrm{~m}$, and (iii) the water level is $5 \mathrm{~m}$. For all three cases, the groundwater level inside the slope (the dashed blue line) is considered to be constant. The distance $d(=0,2,4,6,8$, 10,12 , and $14 \mathrm{~m}$ ) between the building and the slope crest is an important parameter to analyze the differential settlement characteristics of building under three water levels.

4.2. Result Discussion. According to the plastic zone shown in Figure 10, it can be found that the failure mode of soil under the rapid drawdown of water level is similar to that of slope foundation obtained by literatures [37, 38]. The changes of water level will cause the plastic zone changes of slope and building. As the water level of a river decreases, the potential sliding surface of the bank slope becomes more obvious and the maximum shear strain increment becomes larger. At the same time, the existence of slope leads the maximum shear strain increment at the bottom of left pile near the slope to be greater than that of right pile, and the gap between them increases with the decrease of water level.

The displacement distribution is shown in Figure 11. It can be seen that when the water level decreases, the sliding displacement of slope will increase, indicating that the more the water level decreases, the worse the stability becomes. 


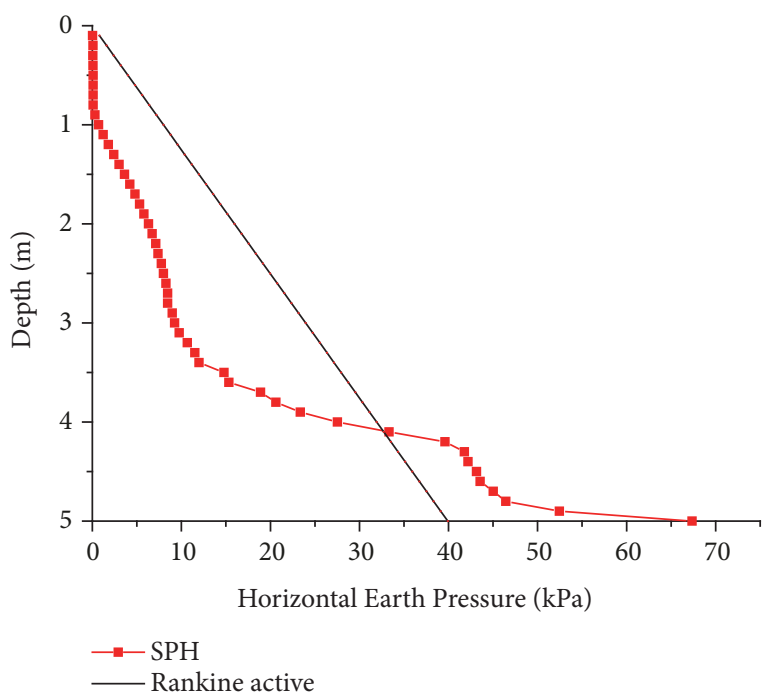

(a) Distribution rules between SPH and Rankine earth pressure theory

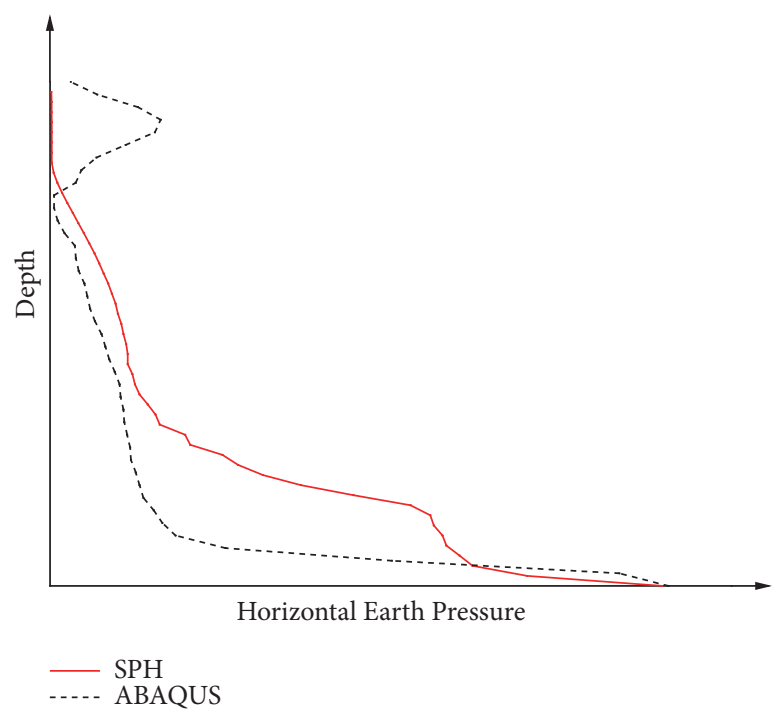

(b) Distribution rules between SPH and FEM [36]

FIGURE 8: Horizontal earth pressure distributed along the depth.

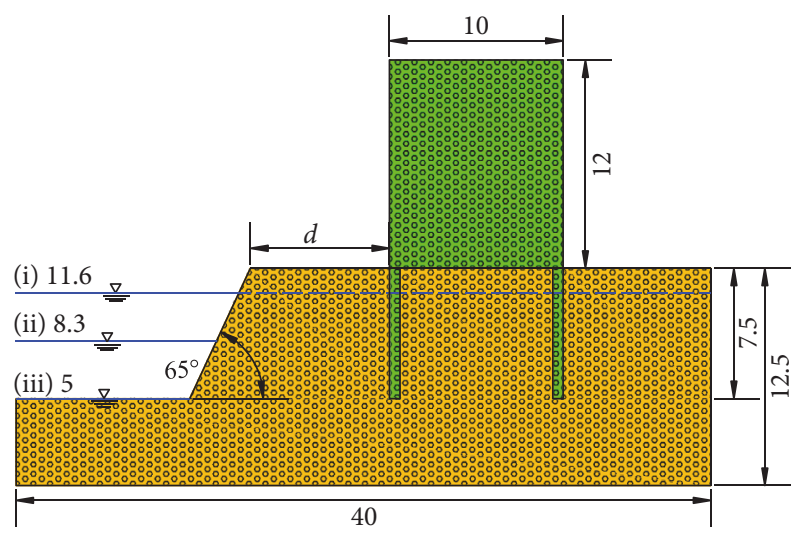

FIGURE 9: Sketch map of model (unit: m).

The displacement on both sides of the building foundation shows that the displacement on the side adjacent to the slope is greater than that on the other side. As the water level decreases, the displacement difference between the two shows an increasing trend.

The displacement at the crest of slope under different water levels is also analyzed, and the comparison shows that the lower the water level is, the greater the displacement at the crest of slope is. The horizontal displacement at the slope crest with the water level of $5 \mathrm{~m}$ increases by $133 \%$ (Figure 12(a)) and the vertical displacement increase by $123 \%$ (Figure 12(b)) compared with the water level of $11.6 \mathrm{~m}$. This is because when the water level drops, the water pressure on the slope decreases, and, as a result, the seepage boundary conditions change as well, which is not conducive to the slope stability. More importantly, the groundwater level inside the slope drops at a significantly lower rate than the water level. The water head difference between inside and outside of the slope is formed, which generates additional seepage pointing to the outside of slope. Under the action of these mechanisms, the slope is prone to be instable. The greater the water level drops, the greater the possibility of slope instability is. Slope displacements do not reach steady state (Figure 12), because water levels drop caused the change of seepage boundary conditions. In this case, only the slope seepage field achieves stability again; the deformation of slope will be stable. However, it will take a very long time to calculate the seepage stability and the stability of the slope is improving during this process [13]. So the most dangerous condition is considered, which does not calculate the long-term changes of seepage.

When the slope is instable, under the action of sliding force, the process in which the sliding body on the sliding surface slides downward is equivalent to the process of soil inside the sliding surface releasing the earth pressure. Under this mechanism, for the building near the crest of the slope, the earth pressure near the crest of the slope is disturbed to a greater extent, which will cause a larger settlement of the building on this side. However, the earth pressure far from the side of the slope is disturbed to a less extent, which will cause a smaller settlement of the building. Thus, it may lead to the differential settlement of the building, which may cause the building to tilt and produce additional stress or increase the additional stress of the superstructure. Figure 13(a) reveals that as the water level goes down, the sliding deformation of slope goes larger, the disturbance of earth pressure goes more obvious, the differential settlement difference of the building goes greater, and the building safety goes down. In addition, it can be seen from the pile lateral displacement curve in Figure 13(b) that, under the condition of different water levels, the deforming characteristics of the piles are generally the same, but the displacement values are slightly different. When the water level decreases, the lateral displacement of the pile 


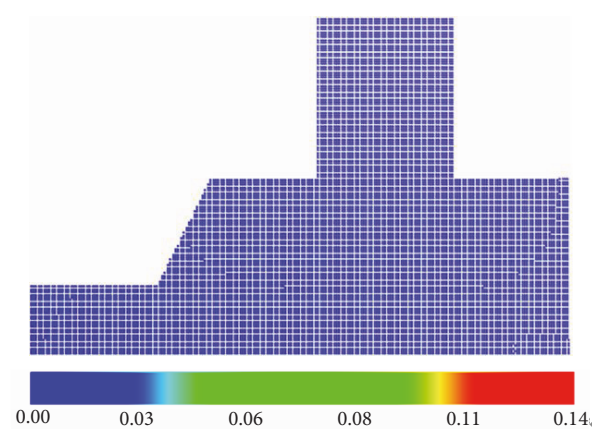

(a) Initial state

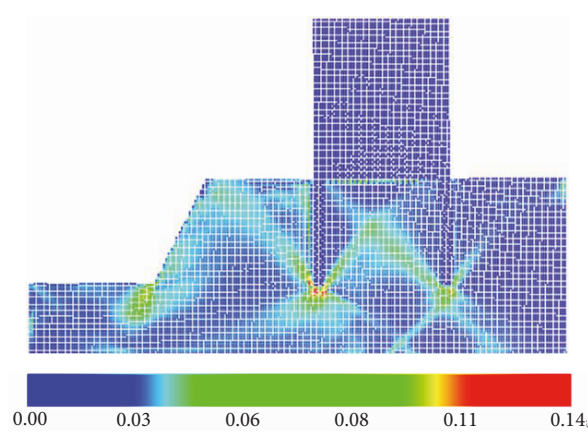

(c) Water level at $8.3 \mathrm{~m}$

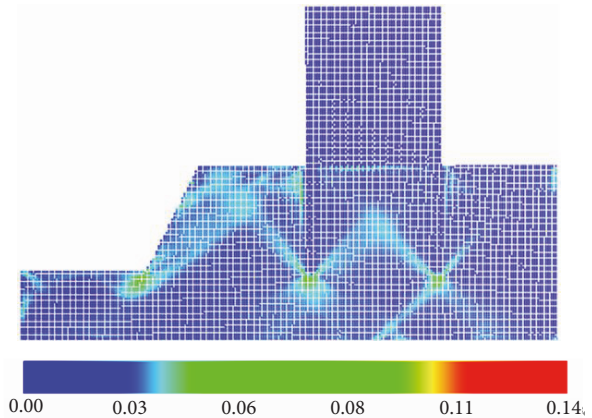

(b) Water level at $11.6 \mathrm{~m}$

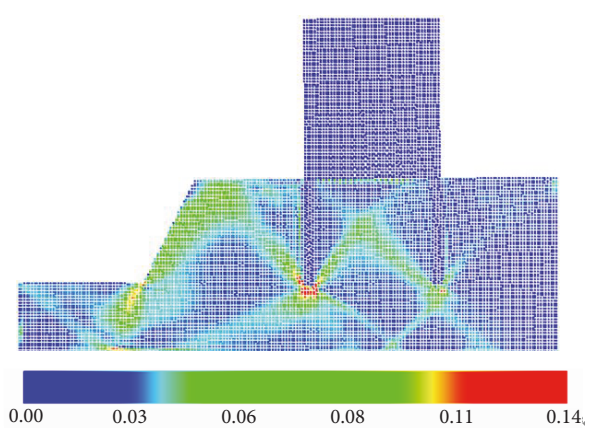

(d) Water level at $5 \mathrm{~m}$

FIGURE 10: Plastic zone at the end of SPH simulations.

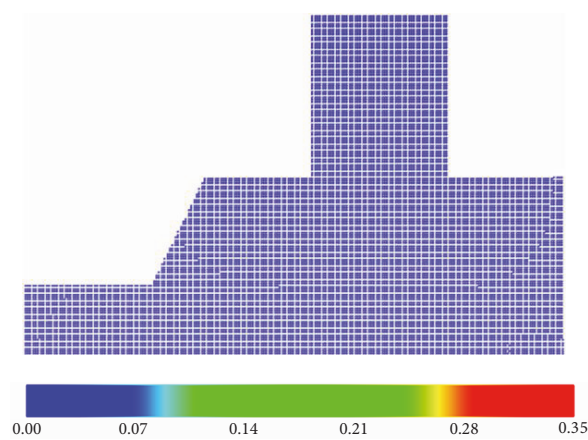

(a) Initial state

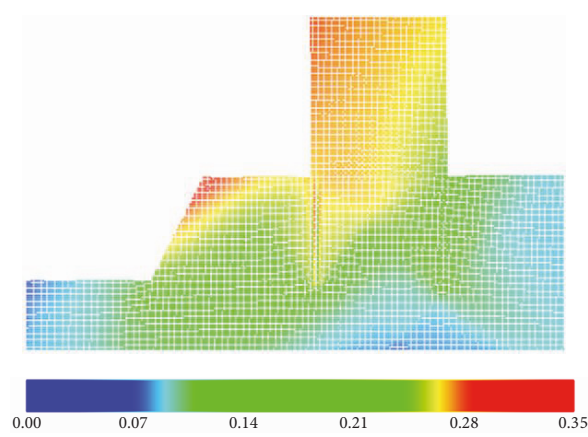

(c) Water level at $8.3 \mathrm{~m}$

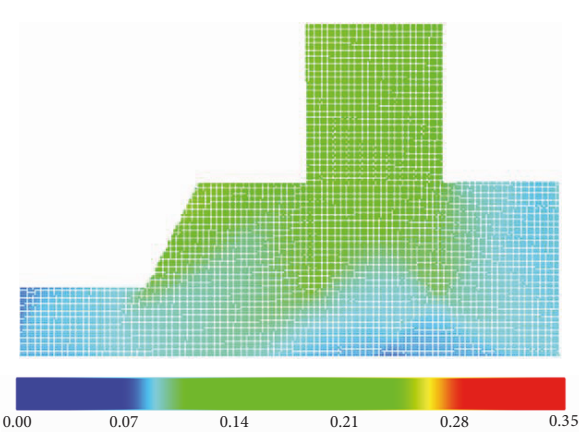

(b) Water level at $11.6 \mathrm{~m}$

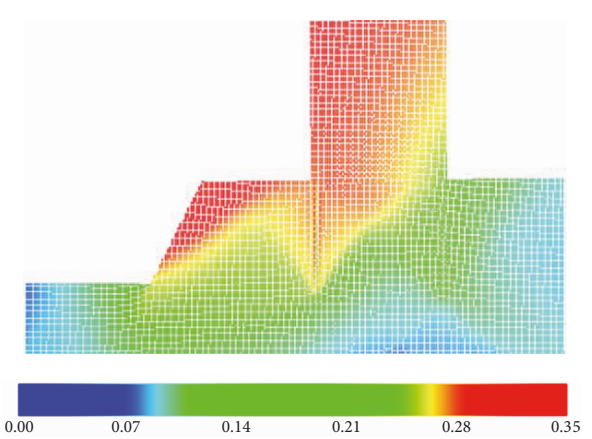

(d) Water level at $5 \mathrm{~m}$

FIGURE 11: Distribution of displacement (unit: m). 


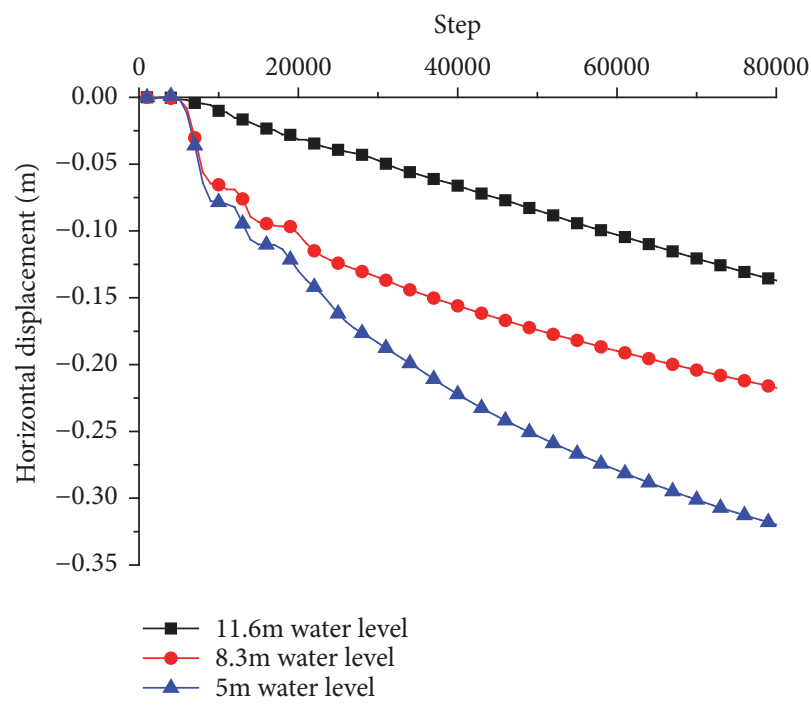

(a) Horizontal displacement of the slope crest

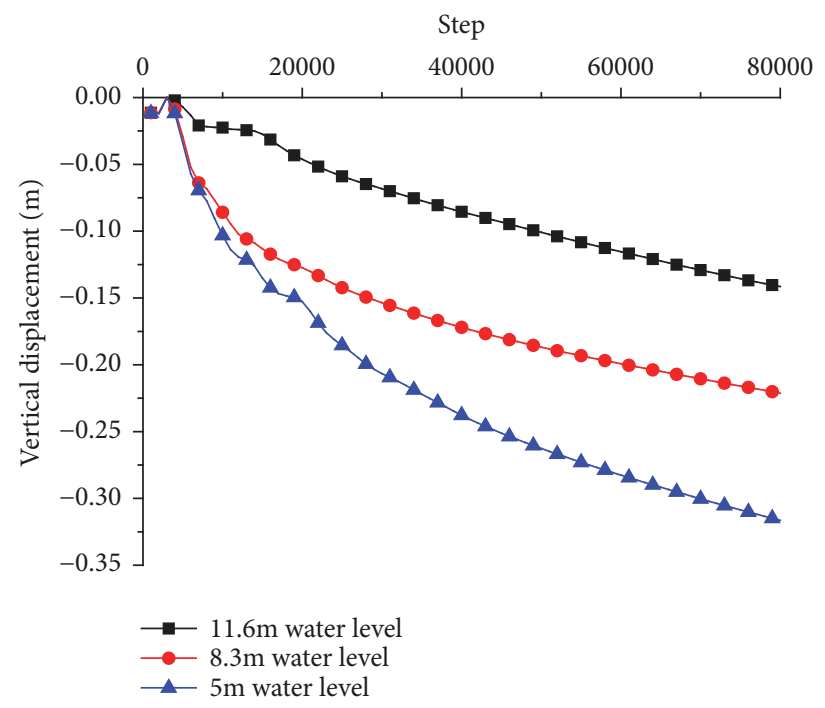

(b) Vertical displacement of the slope crest

FIgURE 12: Time-history curves of displacement at slope crest.

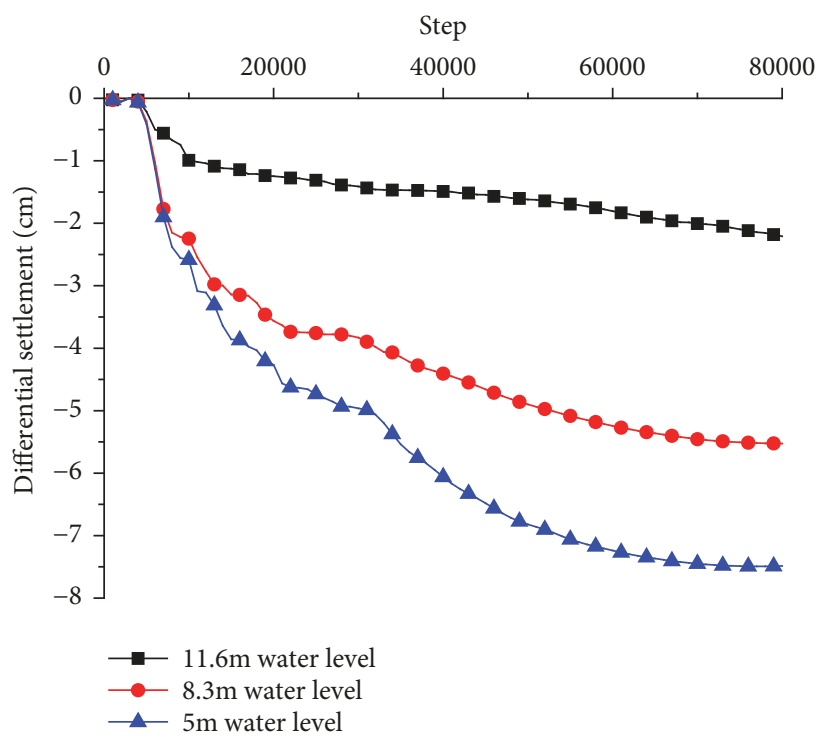

(a) Differential settlement of the building

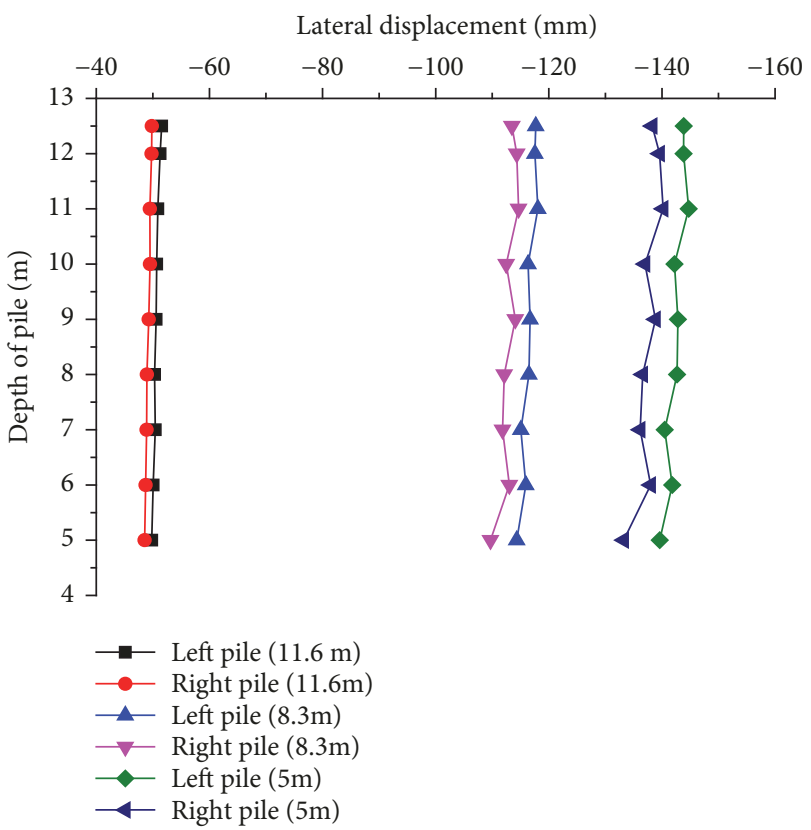

(b) Lateral displacement of the pile

FIGURE 13: Time-history curves of displacement of structure.

will increase. Besides, with the increase of soil depth, the disturbance of soil by the slope sliding decreases and the constraint of soil on the pile increases. It makes the lateral displacement of the pile decrease with the increase of soil depth. The lateral displacement of the pile far away from slope is smaller than that of the pile adjacent to slope and the displacement difference between them increases with the drop of water level.

According to the differential settlement curve under different working conditions in Figure 14, it can be found that the differential settlement of the building decreases with the increase of distance $(d)$ between the building and the slope crest at the same water level. When $d$ is less than or equal to $4 \mathrm{~m}$, the differential settlement of the building is strongly correlated with $d$. When $d$ is more than $4 \mathrm{~m}$, there is a significantly weak correlation between the differential settlement and $d$. According to the plastic zone diagram under different $d$, when $d$ is less than or equal to $4 \mathrm{~m}$, the slope sliding surface passes through the building, and when $d$ is greater than $4 \mathrm{~m}$, the building is outside the slope sliding 


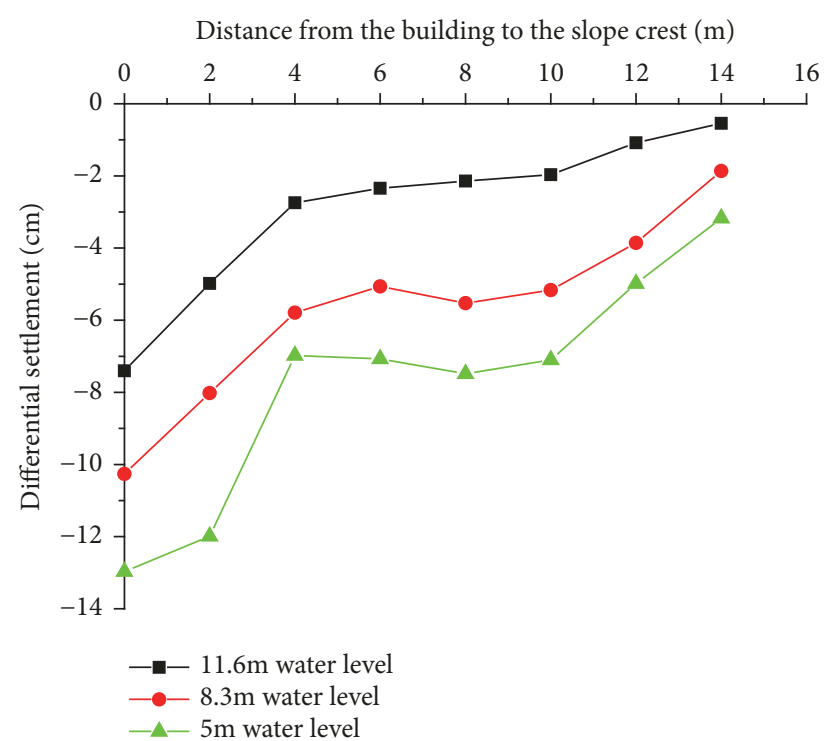

Figure 14: Differential settlement curves of the building under different condition.

surface. It can be seen that when the slope sliding surface passes through the building, its differential settlement will become large.

\section{Conclusion}

Aiming at the problem of the slope-building-coupled failure under the rapid drawdown of water level, this paper took an existing test to verify the feasibility of the proposed SPH model in simulating the soil-water-coupled problem under the rapid drawdown of water level. Then, an example of retaining wall was given to verify the rationality of soilstructure interaction. Besides, the right bank of the Qinhuai river and its ancillary building from the Dinghuai Gate to the Qingliang Gate were analyzed. In the simulation, three different conditions of water level were considered to study the slope-building-coupled failure mechanism and failure mode adjacent to water. Meanwhile, the evolutionary mechanism of slope and building deformation under the rapid drawdown was also revealed. The conclusions could be drawn as follows:

(1) With the rapid drawdown of water level, the potential slip surface of slope and the asymmetrical distribution of plastic zone in the foundation of building become more obvious.

(2) The differential settlement of a building under the rapid drawdown causes the building to tilt and impacts the building utility. In addition, the larger water level drops, the larger differential settlement of the building becomes.

(3) When the sliding surface of slope passes a building, its differential settlement will become large and will be significantly affected by the distance from building to slope crest.

\section{Data Availability}

(1) The [generated] data used to support the findings of this study are included within the article. (2) The [analyzed] data used to support the findings of this study are included within the article. (3) The [nonanalyzed] data used to support the findings of this study are included within the article.

\section{Conflicts of Interest}

The authors declare that they have no conflicts of interest.

\section{Acknowledgments}

This work was supported by the National Key Research and Development Program of China (Grant no. 2016YFC0800205), the National Natural Science Foundation of China (NSFC Grant no. 51808192), the Natural Science Foundation of Jiangsu Province (Grant no. BK20170887), and the Postdoctoral Science Foundation of China.

\section{References}

[1] N. Morgenstern, "Stability charts for earth slopes during rapid drawdown," Géotechnique, vol. 13, no. 1, pp. 121-131, 1963.

[2] F. O. Jones, D. R. Embody, W. L. Peterson et al., "Landslides along the Columbia river valley," Geological Survey Professional Paper 367, Washington, DC, USA, 1961.

[3] N. M. Pinyol, E. E. Alonso, J. Corominas, and J. Moya, "Canelles landslide: modelling rapid drawdown and fast potential sliding," Landslides, vol. 9, no. 1, pp. 33-51, 2012.

[4] W. Jian, Q. Xu, H. Yang, and F. Wang, "Mechanism and failure process of Qianjiangping landslide in the Three Gorges Reservoir, China," Environmental Earth Sciences, vol. 72, no. 8, pp. 2999-3013, 2014.

[5] E. Alonso and N. Pinyol, Slope Stability under Rapid Drawdown Conditions, Universitat Politècnica de Catalunya, Barcelona, Spain, 2009.

[6] C. Viratjandr and R. L. Michalowski, "Limit analysis of submerged slopes subjected to water drawdown," Canadian Geotechnical Journal, vol. 43, no. 8, pp. 802-814, 2006.

[7] Y. Gao, D. Zhu, F. Zhang, G. H. Lei, and H. Qin, "Stability analysis of three-dimensional slopes under water drawdown conditions," Canadian Geotechnical Journal, vol. 51, no. 11, pp. 1355-1364, 2014.

[8] G. W. Jia, T. L. T. Zhan, Y. M. Chen, and D. G. Fredlund, "Performance of a large-scale slope model subjected to rising and lowering water levels," Engineering Geology, vol. 106, no. 12, pp. 92-103, 2009.

[9] S. Naoki, N. Kunitomo, and O. Tetsuo, "Centrifuge tests on seepage behaviour in embankment dams during rapid drawdown," Bulletin of Aichi Institute of Technology, vol. 39, pp. 85-90, 2004 (Japanese).

[10] J.-J. Wang, H.-P. Zhang, L. Zhang, and Y. Liang, "Experimental study on heterogeneous slope responses to drawdown," Engineering Geology, vol. 147-148, pp. 52-56, 2012.

[11] F. Luo and G. Zhang, "Progressive failure behavior of cohesive soil slopes under water drawdown conditions," Environmental Earth Sciences, vol. 75, no. 11, article 973, 2016.

[12] G. Zhang and F. Y. Luo, "Simplified stability analysis of strainsoftening slopes under drawdown conditions," Environmental Earth Sciences, vol. 76, no. 4, article 151, 2017.

[13] M. M. Berilgen, "Investigation of stability of slopes under drawdown conditions," Computers \& Geosciences, vol. 34, no. 2, pp. 81-91, 2007. 
[14] D. V. Griffiths and P. A. Lane, "Slope stability analysis by finite elements," Géotechnique, vol. 49, no. 3, pp. 387-403, 1999.

[15] E. E. Alonso and N. M. Pinyol, "Numerical analysis of rapid drawdown: applications in real cases," Water Science and Engineering, vol. 9, no. 3, pp. 175-182, 2016.

[16] C. S. Desai, "Drawdown analysis of slopes by numerical method," Journal of Geotechnical and Geoenvironmental Engineering, vol. 103, pp. 667-676, 1977.

[17] C. Liang, M. B. Jaksa, B. Ostendorf, and Y. L. Kuo, "Influence of river level fluctuations and climate on riverbank stability," Computers \& Geosciences, vol. 63, pp. 83-98, 2015.

[18] H. H. Bui, R. Fukagawa, K. Sako, and J. C. Wells, "Slope stability analysis and discontinuous slope failure simulation by elasto-plastic smoothed particle hydrodynamics (SPH)," Géotechnique, vol. 61, no. 7, pp. 565-574, 2011.

[19] Y. Huang, Z. Dai, W. Zhang, and M. Huang, "SPH-based numerical simulations of flow slides in municipal solid waste landfills," Waste Management \& Research, vol. 31, no. 3, pp. 256$264,2013$.

[20] C. Zhu, Y. Huang, and L.-T. Zhan, "SPH-based simulation of flow process of a landslide at Hongao landfill in China," Natural Hazards, vol. 93, no. 3, pp. 1113-1126, 2018.

[21] Z. Wang, X. Yu, W. Zhang, F. Zhang, Y. Zhou, and Y. Gao, "SPHbased analysis on the lateral response of pipe culverts in the flowing process of liquefied sand," Mathematical Problems in Engineering, vol. 2019, Article ID 4351501, 12 pages, 2019.

[22] J. J. Monaghan, "Why particle methods work," SIAM Journal on Scientific and Statistical Computing, vol. 3, no. 4, pp. 422-433, 1982.

[23] J. J. Monaghan, "Simulating free surface flows with SPH," Journal of Computational Physics, vol. 110, no. 2, pp. 399-406, 1994.

[24] M. B. Liu, G. R. Liu, and S. Li, "Smoothed particle hydrodynamics - a meshfree method," Computational Mechanics, vol. 33, no. 6, pp. 491-491, 2004.

[25] M. B. Liu, W. P. Xie, and G. R. Liu, "Restoring particle inconsistency in smoothed particle hydrodynamics," Applied Numerical Mathematics, vol. 56, no. 1, pp. 19-36, 2006.

[26] M. B. Liu and G. R. Liu, "Smoothed particle hydrodynamics (SPH): an overview and recent developments," Archives of Computational Methods in Engineering, vol. 17, no. 1, pp. 25-76, 2010.

[27] S. Shao, "Incompressible smoothed particle hydrodynamics simulation of multifluid flows," International Journal for Numerical Methods in Fluids, vol. 69, no. 11, pp. 1715-1735, 2012.

[28] C. Ulrich, M. Leonardi, and T. Rung, "Multi-physics SPH simulation of complex marine-engineering hydrodynamic problems," Ocean Engineering, vol. 64, pp. 109-121, 2013.

[29] Y. Huang, Z. L. Dai, W. J. Zhang et al., Geo-Disaster Modeling and Analysis: An SPH-Based Approach, Springer Natural Hazards, Berlin, Germany, 2014.

[30] E. Francomano and M. Paliaga, "Highlighting numerical insights of an efficient SPH method," Applied Mathematics and Computation, vol. 339, pp. 899-915, 2018.

[31] W. Zhang, H. Zheng, F. Jiang, Z. Wang, and Y. Gao, "Stability analysis of soil slope based on a water-soil-coupled and parallelized Smoothed Particle Hydrodynamics model," Computers \& Geosciences, vol. 108, pp. 212-225, 2019.

[32] J. J. Monaghan, "An introduction to SPH," Computer Physics Communications, vol. 48, no. 1, pp. 89-96, 1988.
[33] W. Zhang, K. Maeda, H. Saito, Z. Li, and Y. Huang, "Numerical analysis on seepage failures of dike due to water level-up and rainfall using a water-soil-coupled smoothed particle hydrodynamics model," Acta Geotechnica, vol. 11, no. 6, pp. 1401-1418, 2016.

[34] H. Takeda, S. M. Miyama, and M. Sekiya, "Numerical simulation of viscous flow by smoothed particle hydrodynamics," Progress of Theoretical and Experimental Physics, vol. 92, no. 5, pp. 939-960, 1994.

[35] J. P. Morris, P. J. Fox, and Y. Zhu, "Modeling low Reynolds number incompressible flows using SPH," Journal of Computational Physics, vol. 136, no. 1, pp. 214-226, 1997.

[36] Q. P. Cai, A study on the earth pressure against rigid and flexible retaining wall [MA. Eng. thesis], Zhejiang University, China, 2007.

[37] K. Georgiadis, "Undrained bearing capacity of strip footings on slopes," Journal of Geotechnical and Geoenvironmental Engineering, vol. 136, no. 5, pp. 677-685, 2010.

[38] Y. Wu, X. Zhou, Y. Gao, L. Zhang, and J. Yang, "Effect of soil variability on bearing capacity accounting for non-stationary characteristics of undrained shear strength," Computers \& Geosciences, vol. 110, pp. 199-210, 2019. 


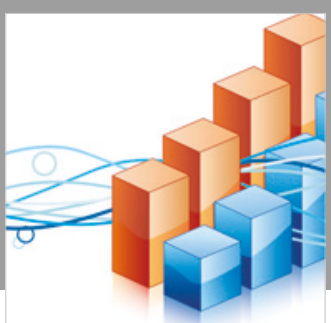

Advances in

Operations Research

\section{-n-m}
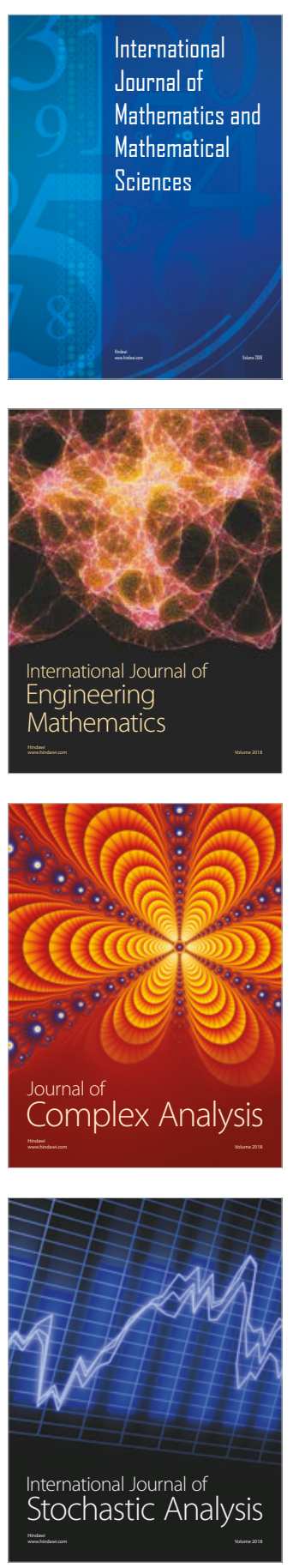
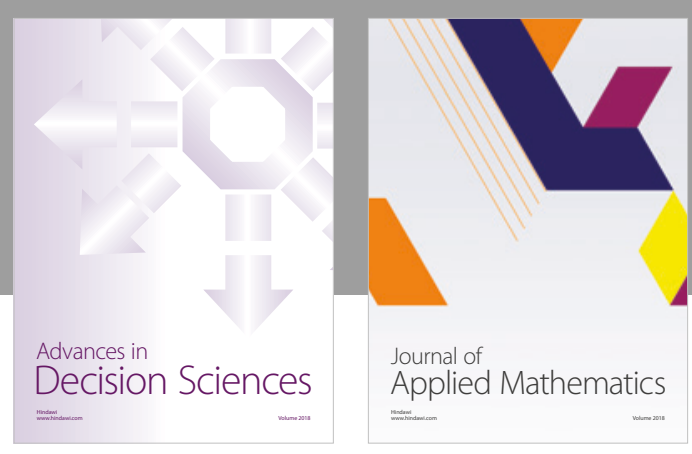

Journal of

Applied Mathematics
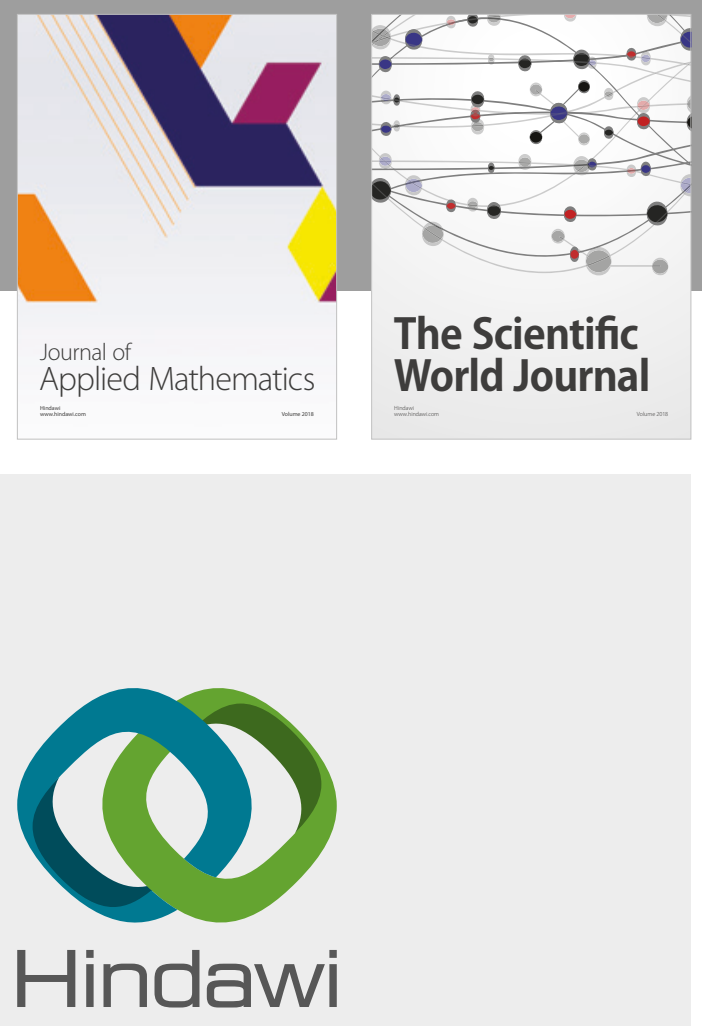

Submit your manuscripts at

www.hindawi.com

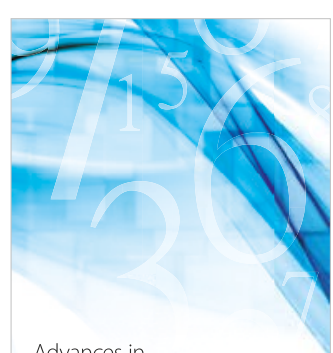

Advances in
Numerical Analysis
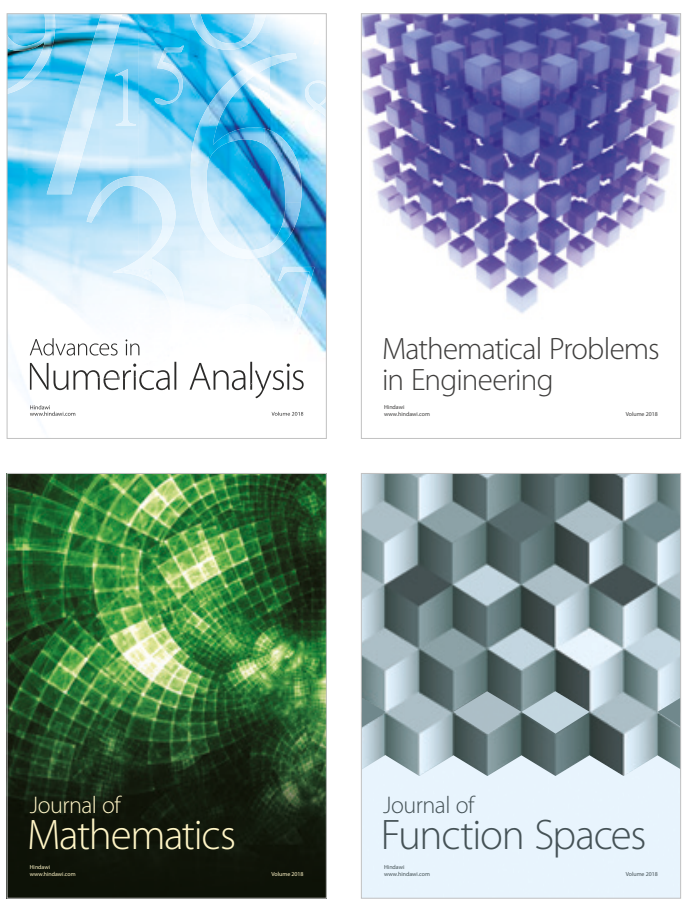

Mathematical Problems in Engineering

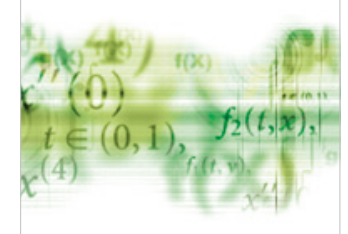

International Journal of

Differential Equations

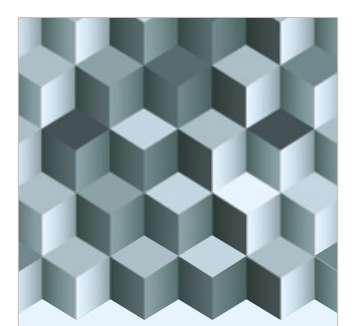

Journal of

Function Spaces

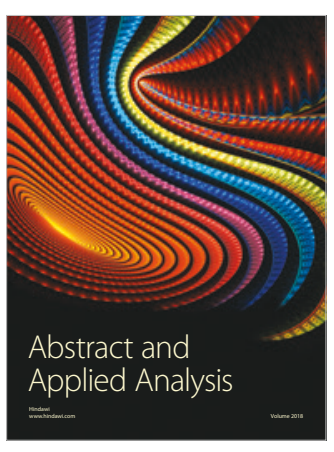

The Scientific

World Journal

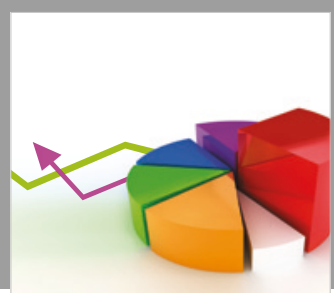

Journal of

Probability and Statistics
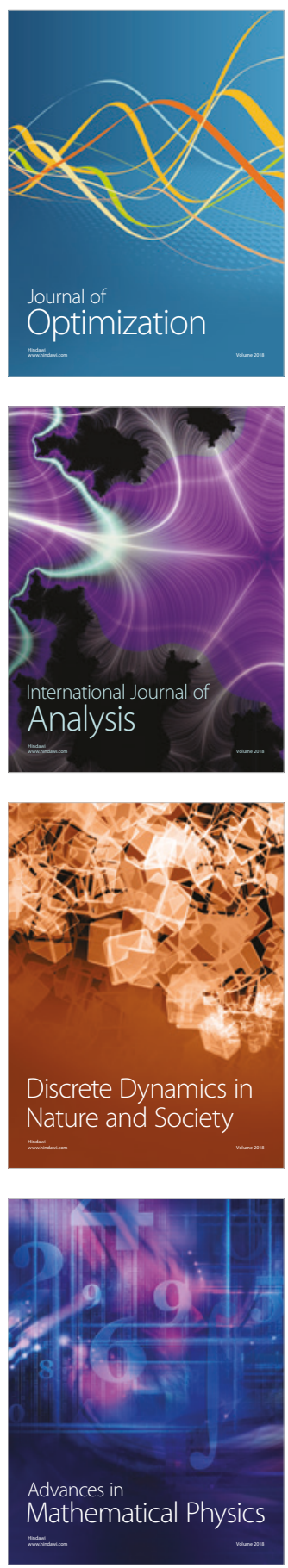